\title{
Vacuum-Distillation Extraction of Selenium from Selenium-Containing Preliminary Products and Materials
}

\author{
Sergey A. Trebukhov*, \\ Valerij N. Volodin, Aleksey A. Trebukhov, \\ Nurila M. Burabaeva and Alina V. Nitsenko \\ «Institute of Metallurgy and Ore Benefication» JSC \\ 29 Shevchenko Str., Almaty, 050010, Kazakhstan
}

Received 08.08.2017, received in revised form 09.09.2017, accepted 11.10.2017

The results of long standing studies by collective of the laboratory of vacuum processes JSC "Institute of Metallurgy and Ore Benefication" provided the basis for the development of environmentally friendly vacuum-distillation technology of selenium extract from the various selenium-containing middling products and materials with further refinement to the slate condition in accordance with GOST 10298-79. The technology and equipment has been tested on different raw materials, including: technical and crude selenium produced by Kazzink LLP and Kazakhmys Corporation LLP, selenium-containing bag filter fumes of refinery production and drilling cutting of sulfuric production produced by Kazakhmys Corporation LLP, sludge of nickel production produced by Kolsky MMC, selenium-containing concentrates Krastsvetmet JSC. Potential of developed vacuum-distillation technology and equipment, allowing to receiving the selenium containing more than $99.5 \%$ of the main component within one step by cheap reagentless method, is shown in this article an example of several form of materials.

Keywords: extraction, selenium, vacuum distillation, refining, sludge, fumes, concentrates.

Citation: Trebukhov S.A., Volodin V.N., Trebukhov A.A., Burabaeva N.M., Nitsenko A.V. Vacuum-distillation extraction of selenium from selenium-containing preliminary products and materials, J. Sib. Fed. Univ. Eng. technol., 2017, 10(7), 932-939. DOI: 10.17516/1999-494X-2017-10-7-932-939.

(C) Siberian Federal University. All rights reserved

* Corresponding author E-mail address: vohubert@mail.ru 


\title{
Вакуум-дистилляционное извлечение селена \\ из селенсодержащих промпродуктов
}

\section{и материалов}

\author{
С.А. Требухов, В.Н. Володин, \\ А.А. Требухов, Н.М. Бурабаева, А.В. Ниценко \\ АO «Институт металлургии и обогащуения» \\ Казахстан, 050010, Алматы, ул. Шевченко, 29
}

Результаты многолетних исследований коллектива лаборатории вакуумных проиессов АО «Институт металлургии и обогащения» легли в основу разработки экологически безопасной вакуум-дистилляционной технологии извлечения селена из различных селенсодержаших промпродуктов и материалов с последующим его рафинированием до марочного состояния в соответствии с ГОСТ 10298-79. Технология и аппаратура апробированы на многих видах материалов, в том числе на техническом и черновом селене, производимом ТОО «Казиинк» и ТОО «Корпоращия Казахмыс», селенсодержащих пылях рукавных фильтров аффинажного производства и шламах сернокислотного производства ТОО «Корпорачия Казахмыс», шламах никелевого производства ГМК «Кольская», селенсодержащих конщентратах ОАО «Красиветмет». В данной работе на примере нескольких видов материалов показана эффективность разработанной вакуум-дистилляционной технологии и аппаратуры, позволяюших получать в одну стадию дешёвым безреагентным способом марочный селен с содержанием более 99,5\% основного компонента.

Ключевые слова: извлечение, селен, вакуум, дистилляция, рафинирование, иламы, пыли, концентраты.

\section{Введение}

Селен имеет различные области применения, основными из которых являются электротехническая, металлургическая, стекольная и резиновая промышленности. Например, селен используется в преобразовательной технике в выпрямительных полупроводниковых диодах, а также для фотоэлектрических приборов, электрофотографических копировальных устройств, синтеза различных селенидов, в качестве люминофоров в телевидении, оптических и сигнальных приборах, терморезисторах и т.д. Широко применяется селен для обесцвечивания зеленого стекла и получения рубиновых стекол. В металлургии селен используется для придания литой стали мелкозернистой структуры, улучшения механических свойств нержавеющих сталей, в химической промышленности - в качестве катализатора.

Известно около 40 редко встречающихся минералов селена (селенидов), представляющих собой аналоги сульфидов, самыми распространенными из которых являются клаусталит $(\mathrm{PbSe})$ и клокманит (CuSe). Собственные месторождения селен образует крайне редко, поэтому этот элемент добывается попутно при металлургической переработке медных, медно-никелевых и свинцово-цинковых концентратов.

В настоящее время основным сырьевым источником селена являются шламы медеэлектролитных производств [1]. Однако по мере внедрения технологий получения меди по схеме обжиг-выщелачивание-электроэкстракция, исключающих образование шламов электролиза,

$$
-933-
$$


всё более актуальными становятся вопросы разработки технологий извлечения селена из других источников $[2,3]$, в том числе и из продуктов газоочистки медно-никелевого и аффинажного производств.

Для очистки технического селена от примесей разработаны разнообразные схемы и аппараты, обеспечивающие резкое увеличение его производства и улучшения качества [4] и основанные на химических, физических и комбинированных методах рафинирования [5-12]. При этом химические методы рафинирования селена чаще всего подготовительная операция в процессе его доводки от технического до марочного. Однако многие из них не нашли промышленного применения, что связано с многостадийностью, высокой себестоимостью процессов из-за применения большого числа дорогостоящих реагентов, трудоемкостью, длительностью и низкой производительностью.

Наиболее чистый селен получают сочетанием химических и физических методов очистки, причем физические методы (например, вакуумная дистилляция) применяются на последней стадии.

\section{Вакуум-дистилляционное извлечение селена}

В лаборатории вакуумных процессов АО «Институт металлургии и обогащения» (г. Алматы, Республика Казахстан) на протяжении ряда лет проводятся теоретические исследования по изучению поведения селена, его соединений и примесных элементов во время нагрева при пониженном давлении (0,13-13,3 кПа). На основании полученных данных разработана безреагентная вакуум-дистилляционная технология извлечения селена из различных селенсодержащих промпродуктов и материалов с получением марочного металла, содержащего более 99,5-99,8 \% основного компонента [10]. Технология и аппаратура апробированы на многих видах материалов, в том числе на техническом селене (содержащем 95 \% Se), производимом ТОО «Казцинк», на черновом селене (содержащем 80 \% Se), производимом ТОО «Коропорация Казахмыс», на селенсодержащих пылях рукавных фильтров аффинажного производства (содержащих до $40 \% \mathrm{Se}$ ) и шламах сернокислотного производства (содержащих до $10 \% \mathrm{Se}$ ), получаемых на Балхашском медеплавильном заводе ТОО «Коропорация Казахмыс», на шламах никелевого производства ГМК «Кольская» (содержащих 8-12 \% Se) и на селенсодержащих концентратах $\mathrm{OAO}$ «Красцветмет» (содержащих до 80 \% Se). Технология является экологически безопасной, а аппаратура зарекомендовала себя высокой надёжностью и простотой в обслуживании.

Технологическая схема (рис.) извлечения селена предусматривает стадию предварительной подготовки сырья, дальнейшее зейгерование материала с последующей вакуумной дистилляцией получаемого расплава. Рафинированный селен разливается в слитки массой 5-8 кг, по чистоте металл соответствует марочному селену по ГОСТ 10298-79.

В укрупненном масштабе аппаратура испытана при рафинировании чернового селена ТОО «Казахмыс Смэлтинг» [11]. Было переработано 342,55 кг некондиционного чернового селена влажностью 18,78 \% (278,22 кг по сухой массе), содержащего 82,4 \% основного компонента. После приёмной плавки было получено 196,15 кг переплавленного селена, содержащего 95,12 \% основного компонента, и 52,05 кг шлака, содержащего 63,95 \% Se. При вакуумном дистилляционном рафинировании переплавленного селена получено 185,05 кг рафинированного металла, содержащего 99,633 \% основного компонента, соответствующего марке СТ1 и предназначен- 
ного на экспорт, и 1,1 кг сухого остатка, содержащего 1,63 \% Ag и 50 г/т Au. При дистилляции шлаков, полученных в результате приёмной плавки, дополнительно получено 29,95 кг селена, содержащего 99,15 \% основного компонента, и 20,91 кг остатка следующего состава, \% (мас.): 8,845-43,93 Se; $1,8 \mathrm{Ag}$ и 50 г/т Аu. Несмотря на повышение сквозного извлечения селена при дистилляции шлаков более чем на 12 \% (с 80,42 до 93,37 \%), полученный селен не соответствует марочному, а переработка этих шлаков оказывает повышенное коррозионное воздействие на вакуумное оборудование. Поэтому наиболее целесообразным представляется направлять шлаки приёмной плавки совместно с сухим остатком на повторную переработку в печь Калдо.

Возможность применения разработанных технологии и аппаратуры для извлечения селена из промпродуктов была изучена применительно к селенсодержащему концентрату, получаемому на ОАО «Красцветмет» (г. Красноярск, Россия). Селен (68,567 мас. \%.) в представленном концентрате находился в основном в элементной форме, что дало возможность применения вакуумной отгонки. Однако наличие трудноудаляемых примесей теллура и ртути в исходном материале исключает получение марочного селена в одну стадию [12].

Применительно к указанным концентратам была опробована организация предварительной стадии отмывки концентрата с последующей сушкой, а также предварительная приёмная плавка исходного материала при атмосферном давлении, совмещающая в себе сушку материала, расплавление и его фильтрацию.

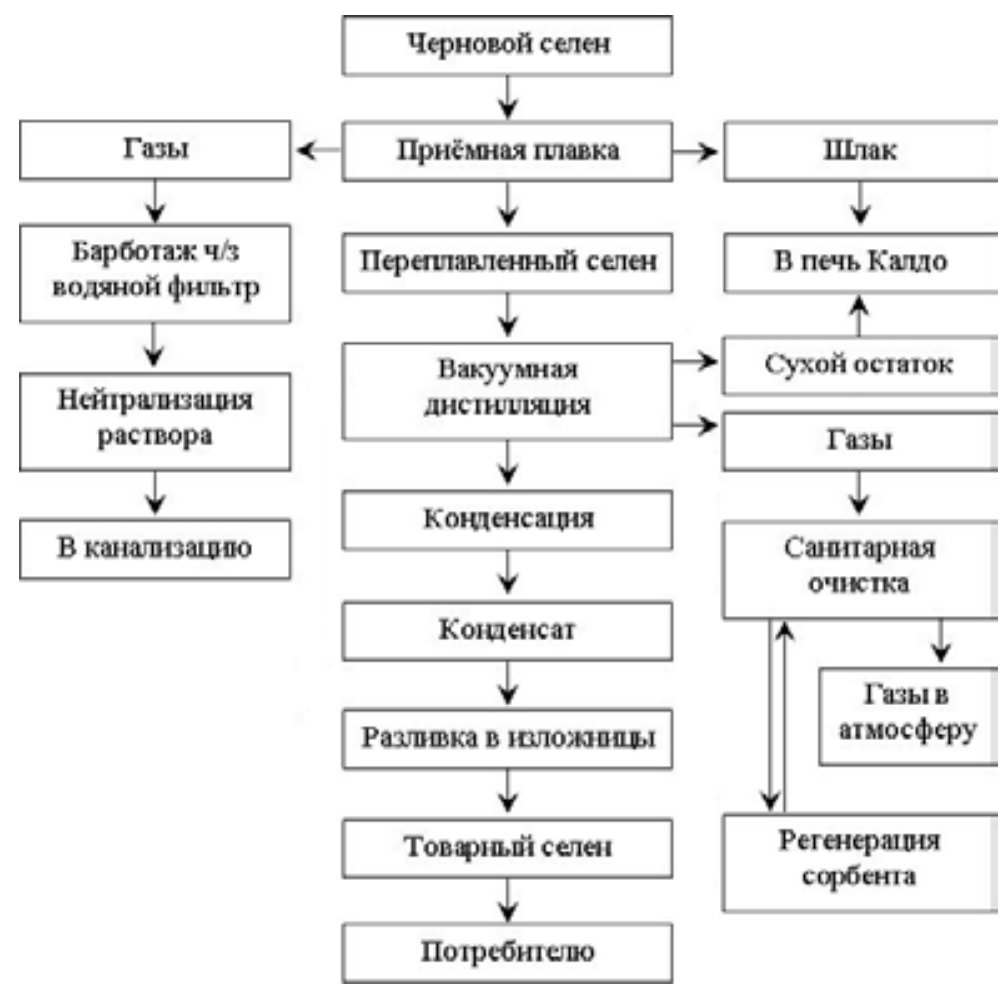

Рис. Технологическая схема получения марочного селена из чернового методом вакуумной дистилляции

Fig. Process Flow Chart of top-quality selenium production from the crude one by vacuum distillation 
Результаты проведенного рентгено-флуоресцентного анализа продуктов исходных материалов и продуктов переработки показали предпочтительность переработки селенсодержащего промпродукта по схеме с предварительной отмывкой и последующим дистилляционным переделом, что обусловлено максимально достигнутой концентрацией драгоценных металлов в остатке и получением селенового конденсата с малым выходом легких фракций.

Также были проведены исследования по извлечению селена из пылей рукавных фильтров печи Калдо и шламов сернокислотного производства, получаемых на Балхашском медеплавильном заводе ТОО «Казахмыс Смэлтинг» [13, 14].

Результаты исследования состава пылей рукавных фильтров показали, что усреднённое содержание селена в них более 30 \%. Материал также содержит значительное количество драгоценных металлов: более 50 г/т золота и $2 \%$ серебра. Содержание теллура в пылях было более $2 \%$.

При изучение поведения селена в условиях приёмной плавки при атмосферном давлении было установлено, что полученный расплав содержал на 5,5 \% Se больше, чем в исходном материале, а содержание тугоплавких соединений значительно снизилось. В результате последующей вакуумной дистилляции полученного расплава содержание селена в конечном продукте составило более 99,5 \%, что соответствует марке СТ1 по ГОСТ 10298-79. В остатке от дистилляции сконцентрировались драгоценные металлы, поэтому его целесообразно возвращать в печь Калдо.

Следует отметить, что сквозное извлечение селена в марочный металл по схеме приёмная плавка-вакуумная дистилляция равно немногим больше 50 \%, что объясняется наличием легколетучего диоксида селена, который теряется с отходящими газами приёмной плавки. Поэтому был опробован способ прямой вакуумной дистилляции без предварительной приёмной плавки.

Полученные результаты показали возможность получения селена данным методом. Но несмотря на то что конденсат по содержанию основного компонента и регламентируемых ГОСТом примесей соответствует марочному селену (содержание Se до 99,8 \%), он имеет ноздреватую структуру и матовую поверхность, что не отвечает требованиям, предъявляемым к товарному продукту. Это связано с возгонкой и конденсацией имеющегося диоксида селена совместно с элементным селеном, которые снижают содержание основного элемента и создают пористую структуру.

Для получениям марочного селена товарного вида при максимальном его извлечении исходные пыли предварительно подвергали водному выщелачиванию с целью перевода диоксида селена в селенистую кислоту. Полученный в результате фильтрации кек и осаждённый из фильтрата элементный селен высушивали и подвергли последующей вакуумной дистилляции. Полученный таким образом конденсат содержал 99,75 \% селена, что соответствует селену марки CT1, предназначенному на экспорт. Продукт имел плотную структуру, характерный металлический блеск и зеркальную поверхность. Сквозное извлечение селена в товарный продукт составило 95,1\%.

Определение возможности использования вакуумной дистилляции для извлечения селена из шламов сернокислотного производства было изучено на материале, содержащем до 11,5 \% селена, который находился в сырье в основном в элементной форме. Особенностью данных шламов является наличие наиболее трудноотделимой составляющей - селенида ртути.

$$
-936-
$$


Процесс извлечения селена из шламов сернокислотного производства проводили по стандартной схеме: приёмная плавка-вакуумная дистилляция. Установлено, что при найденных оптимальных технологических параметрах вакуумной отгонки селена из шламов степень извлечения Se превышает 93 \%. Полученный селен по большинству примесей, регламентируемых ГОСТом, соответствует марке СТ0, однако из-за повышенного содержания ртути он не марочный. Как было показано в работе [15], селенид ртути при нагревании в вакууме испаряется конгруэнтно, поэтому отделить его от элементного селена вакуумной дистилляцией крайне трудно. В связи с этим дальнейшее рафинирование селена, полученного из шламов сернокислотного производства, можно осуществить традиционными химическими методами или, что является более рациональным, направить полученный селенсодержащий продукт в голову процесса селенового передела - в печь Калдо, что заметно не скажется на циркуляционной нагрузке и позволит дополнительно получать около 5 т чернового селена из ранее складируемого продукта.

\section{Выводы}

Таким образом, на примере селенсодержащих концентратов ОАО «Красцветмет», черновом селене, шламах сернокислотного производства и пылях аффинажного производства ТОО «Корпорация «Казахмыс» показана перспективность разработанных в АО «Институт металлургии и обогащения» технологии и аппаратуры для получения марочного селена из различных селенсодержащих материалов вакуум-дистилляционным способом, позволяющим в одну стадию получать селен, содержащий более 99,5 \% основного компонента, который востребован на всех мировых рынках металлов.

\section{Список литературы}

[1] Чернышев А. А., Петров Г. В., Беленький А. М., Ковалев В. Н., Куколевский А. С. Переработка медных шламов: современное состояние и перспективы. Металлург, 2009, 5, 54-56 [Chernyshev A. A., Petrov G. V., Belen'kij A. M., Kovalev V. N., Kukolevskij A. S. Recycling of copper sludge: current status and prospects. Metallurgist, 2009, 5, 54-56 (in Russian)].

[2] Наумов А. В. Состояние и перспективы мирового рынка селена. Цветная металлургия, 2007, 5, 12-20 [Naumov A. V. Status and prospects of global selenium market. Nonferrous metals, 2007, 5, 12-20 (in Russian)].

[3] Наумов А. В., Наумова М. А. Мировые рынки селена и теллура: Их состояние, кризис и его последствия. Цветные металль, 2010, 11, 6-10 [Naumov A. V., Naumova M. A. Selenium and tellurium world markets: Their condition, crisis and its consequences. Nonferrous metals, 2010, 11, 6-10 (in Russian)].

[4] Исакова Р. А., Резняков А. А., Спивак М. М. Рафинирование селена. Алма-Ата: Наука, 1975, 107 c [Isakova R.A., Reznyakov A.A, Spivak M.M. Selenium refining. Alma-Ata, Nauka, 1975, 107 p. (in Russian)].

[5] Кудрявцев А. А. Химия и технология селена и теллура. М.: Высшая школа, 1961, 286 с [Kudryavtsev A. A. Chemistry and technology of selenium and tellurium. Moscow, Vysshaya shkola, 1961, 286 p (in Russian)].

$$
-937-
$$


[6] Ванюков А. В., Перанузов Е. П., Керножицкий В. К. Получение чистого селена через его оксихлорид. Халькогениды циинка, кадмия и ртути, М.: Металлургия, 1973, 12 [Vanyukov A. V., Peranuzov E. P., Kernozhickij V. K. Obtaining pure selenium through its oxychloride. Chalcogenides of zinc, cadmium and mercury, Moscow, Metallurgiya, 1973, 12 (in Russian)].

[7] Сафонов В. В., Киндяков П. С. Получение селена высокой чистоты из технического селена методом хлорирования его в соляной кислоте газообразным хлором. Известия ВУЗов. Цветная металлургия, 1961, 1, 107 [Safonov V. V., Kindyakov P. S. Preparation of high purity selenium from selenium maintenance by chlorination it in hydrochloric acid with chlorine gas. Proceedings of Higher Schools. Nonferrous Metallurgy, 1961, 1, 107 (in Russian)].

[8] Шкуропатенко В. А., Лавренович А. Г., Лавренович Ю. С. Переработка отходов селеновых электрофотографических носителей физическими методами. Вопросы атомной науки и техники. Сер. 13: вакуум, чистые материаль, сверхпроводники, 2003, 5, 19-23 [Shkuropatenko V. A., Lavrenovich A. G., Lavrenovich Yu. S. Waste of selenium electrophotographic carrier by physical methods. Queries of atomic science and technology. Ser. 13: vacuum, pure materials, superconductors, 2003, 5, 19-23 (in Russian)].

[9] Ажажа В. М., Папиров И. И., Шкуропатенко В. А., Лавренович А. Г., Вирич В. Д. Рафинирование вторичного селена дистилляционными методами. Bопросы атомной науки и техники. Сер. 13: вакуум, чистые материалы, сверхпроводники, 2004, 5, 21-23 [Azhazha V. M., Papirov I. I., Shkuropatenko V. A., Lavrenovich A. G., Virich V. D. Refining of secondary selenium by distillation methods. Queries of atomic science and technology. Ser. 13: vacuum, pure materials, superconductors, 2004, 5, 21-23 (in Russian)].

[10]Инн. патент 28695 РК. Способ извлечения селена из селенсодержащих продуктов. Храпунов В. Е., Требухов С. А., Марки И. А., Ниценко А. В., Адылканова М. А., опубл. 15.07.14, Бюл. 7, $3 c$ [Innovative patent 28695 Republic of Kazakhstan. The method of selenium extract from seleniumcontaining products. Khrapunov V. E., Trebukhov S. A., Marki I. A., Nitsenko A. V., Adylkanova M. A., publ. 15.07.14, Bull. 7, 3 p. (in Russian)].

[11] Храпунов В. Е., Требухов С. А., Марки И. А., Адылканова М. А., Калдыбеков Ф. Х. Укрупнённые испытания вакуум-дистилляционного рафинирования некондиционного чернового селена. Цветные металлы, 2013, 7, 75-80 [Khrapunov V. E., Trebukhov S. A., Marki I. A., Adylkanova M. A., Kaldybekov F. H. Enlarged trials of vacuum distillation refining of crude selenium substandard. Nonferrous metals, 2013, 7, 75-80 (in Russian)].

[12]Требухов С. А., Требухов А. А., Тулеутай Ф. Х., Ниценко А. В. Извлечение селена из селенсодрежащих концентратов ОАО «Красцветмет» с получением обогащенных драгметаллами остатков. Доклады VII Международного конгресса «Цветные металлы и минеральз», Красноярск, 2015, 867-873 [Trebukhov S. A., Trebukhov A. A., Tuleutaj F. Kh., Nitsenko A. V. Extraction of selenium from selenium-containing concentrates produced by OJSC "Krastsvetmet" with the receipt of residues enriched with precious metals. Proceedings of the VII International Congress «Non-Ferrous Metals and Minerals», Krasnoyarsk, 2015, 867-873 (in Russian)].

[13]Храпунов В. Е., Требухов С. А., Адылканова М. А., Тулеутай Ф. Х., Марки И. А. Исследование по получению марочного селена из пылей рукавных фильтров аффинажного производства. Комплексное использование минерального сырья, 2013, 4, 52-57 [Khrapunov V. Е., Trebukhov S. A., Adylkanova M. A., Tuleutaj F. Kh., Marki I. A. Study of selenium production from 
branded dust bag filters produced by refining industry. Complex Use of Mineral Resources, 2013, 4, 52-57 (in Russian)].

[14]Храпунов В. Е., Требухов С. А., Марки И. А., Тулеутай Ф. Х., Требухов А. А. Извлечение селена из шламов сернокислотного производства вакуумным методом. Комплексное использование минерального сырья, 2014, 4, 42-48 [Khrapunov V. E., Trebukhov S. A., Marki I. A., Tuleutaj F. Kh., Trebukhov A. A. Removing of selenium from sulfuric acid production sludge by vacuum. Complex Use of Mineral Resources 2014, 4, $42-48$ (in Russian)].

[15]Молдабаев М., Абрамов А. С., Храпунов В. Е., Марки И. А., Требухов С. А., Садвакасов Д. А. Термическое поведение селенида ртути в вакууме. Комплексное использование минерального сырья, 2003, 3, 37-41 [Moldabaev M., Abramov A. S., Khrapunov V. E., Marki I. A., Trebukhov S. A., Sadvakasov D. A. The thermal behavior of mercury selenide in a vacuum. Complex Use of Mineral Resources, 2003, 3, 37-41 (in Russian)]. 